\title{
PERENCANAAN STRATEGIS SISTEM INFORMASI MENGGUNAKAN METODOLOGI WARD AND PEPPARD PADA SMPN 4 SALATIGA
}

\author{
Theresia Triyuni $i^{1)}$ dan Agustinus Fritz Wijaya $\left(^{2)}\right.$ \\ ${ }^{1,2)}$ Sistem Informasi, Fakultas Teknologi Informasi, Universitas Kristen Satya Wacana \\ ${ }^{1,2)}$ Jl. Dr. O. Notohamidjojo No. 1, Salatiga, 50715 \\ E-mail :682017019@student.uksw.edu ${ }^{1)}$,agustinus.wijaya@uksw.edu ${ }^{2}$
}

\begin{abstract}
ABSTRAK
Pada saat ini perkembangan teknologi menuntut perusahaan atau organisasi harus mampu beradaptasi sehingga dapat bersaing dengan perusahaan lainnya. Perencanaan strategis sistem informasi menjadi sangat berpengaruh agar dapat bertahan di dalam persaingan bisnis. SMP Negeri 4 Salatiga merupakan lembaga pendidikan yang sudah menerapkan sistem informasi tetapi belum maksimal penerapannya karena belum terintegrasi sehingga menjadi tidak efisien dalam menjalankan dan mendukung proses bisnisnya. Oleh karena itu, untuk memaksimalkan penerapan sistem informasi maka perlu perencanaan strategis sistem informasi untuk mencapai visi misi dan tujuan pada SMP Negeri 4 Salatiga. Dalam penyusunan rencana strategis sistem informasi di SMP Negeri 4 Salatiga menggunakan kerangka kerja Ward and Peppard dengan alat bantu analisis yaitu: Value Chain untuk menganalisis lingkungan bisnis internal dan eksternal, SWOT untuk menganalisis lingkungan internal dan eksternal sistem informasi, McFarlan Strategic Grid untuk memetakan portofolio aplikasi sistem informasi saat ini dan yang akan datang di SMP Negeri 4 Salatiga. Untuk memaksimalkan penerapan sistem informasi pada SMP Negeri 4 Salatiga, terdapat rekomendasi sistem informasi yang diberikan seperti Sipras, Sikewa, Sikelulusan, Sialumni dan E-Learning. Kemudian terdapat pemetaan implementasi aplikasi berdasarkan prioritas yang nantinya membantu dalam mengambil keputusan pengimplementasian aplikasinya. Dari beberapa rekomendasi serta pemetaan implementasi aplikasi ini diharapkan sebagai bahan acuan implementasi pengembangan sistem informasi yang akan datang SMP Negeri 4 Salatiga.
\end{abstract}

Kata Kunci: Perencanaan Strategis, Sistem Informasi, Value Chain, SWOT, McFarlan Strategic, Ward Peppard

\section{PENDAHULUAN}

Pada saat ini perkembangan teknologi yang cepat menyebabkan persaingan bisnis semakin ketat sehingga tidak bisa dipungkiri bahwa teknologi informasi sangat mempengaruhi pola kehidupan, terutama pada dunia bisnis (Manoppo, 2017). Banyak organisasi perusahaan, lembaga pendidikan, pemerintahan sudah menerapkan dan memanfaatkan teknologi informasi untuk menunjang proses bisnisnya. Dengan adanya teknologi dalam menjalankan bisnis akan mempermudah suatu proses bisnis dan berpengaruh terhadap keunggulan kompetitif suatu perusahaan atau organisasi (Johannis, dkk, 2019).

Sistem informasi dan teknologi informasi sangat berperan dan tidak terlepas dalam kegiatan bisnis, hal ini dikarenakan sistem informasi dapat membantu dalam pengambilan keputusan, meningkatkan kualitas layanan kepada konsumen, memperluas pasar dan pemasaran produk dan merealisasikan tujuan organisasi. Dengan mengetahui kebutuhan bisnis dan sumber daya teknologi informasi maka dapat melihat suatu peluang yang dapat dimanfaatkan sebagai lonjakan (Karsana, dkk, 2019). Dengan penggunaan sistem informasi sebagai komponen utama maka harus dimanfaatkan secara optimal untuk bisa bersaing dengan para kompetitor dan perlunya strategi sistem informasi yang matang (Setiyanti, dkk, 2016).
SMP Negeri 4 Salatiga merupakan lembaga pendidikan yang telah menerapkan sistem informasi namun belum terintegrasi dan belum dimanfaatkan secara maksimal dalam menjalankan dan mendukung proses operasionalnya. Hal ini menyebabkan proses bisnis tidak efisien dan terhambat terutama pada aktivitas bisnis utama maupun aktivitas bisnis pendukung. Oleh karena itu, SMP Negeri 4 Salatiga memerlukan adanya perencanaan strategi bisnis maupun strategi sistem informasi untuk memaksimalkan penerapan sistem informasi supaya selaras dan terintegrasi antar proses bisnis, meningkatkan efisiensi kinerja dalam mencapai tujuan visi dan misinya serta meningkatkan daya saing.

Di dalam penelitian sebelumnya berjudul Perencanaan Strategi Sistem Informasi Dalam Kegiatan Penelusuran Minat Siswa Sekolah Menengah Pertama, disimpulkan bahwa dengan adanya perencanaan strategis sistem informasi, sekolah sudah dianggap mampu dalam memenuhi kebutuhan yang diharapkan sekolah tersebut dengan adanya peningkatan efektifitas dan efisiensi. Namun di dalam penelitan tersebut hanya spesifik membahas mengenai perencanaan strategi sistem informasi hanya salah satu proses bisnis yang dilakukan sekolah tersebut (Handayani, 2018).

Penelitian lainnya dengan judul Strategi Peningkatan Mutu Sekolah Berdasarkan Analisis SWOT di Sekolah 
Menengah Pertama (SMPN 1 Bawen) dengan tujuan untuk mendeskripsikan faktor-faktor apa saja yang menjadi kekuatan, kelemahan, peluang dan ancaman dalam peningkatan mutu serta menyusun strategi yang perlu dilakukan untuk meningkatkan mutu SMPN 1 Bawen. Dimana hasil analisis SWOT adalah untuk meningkatkan kualitas sekolah menyatakan posisi SMPN 1 Bawen berada pada kuadran SO, yang mendukung strategi agresif untuk mendukung pertumbuhan sekolah dibuat rencana strategis yang memanfaatkan kekuatan untuk menangkap peluang yang ada. Draf aspek strategis: input, proses, dan output meliputi: mengembangkan lingkungan sekolah yang ideal, melalui program $7 \mathrm{~K}$ (Kesehatan, Ketertiban, Kecantikan, Naungan, Keamanan, Kenyamanan, dan Kekeluargaan; Optimalisasi program pengembangan profesional guru, dan meningkatkan prestasi akademik dan non-akademis seoptimal mungkin (Sujoko, 2017).

Penelitian lainnya yang terkait tentang perencanaan strategis sistem informasi dengan judul Perencanaan Strategis Sistem Informasi Untuk Meningkatkan Layanan Pendidikan Menggunakan Metode Ward And Peppard (Studi Kasus : SMK Swasta di Surabaya) membahas tentang perencanaan strategis sistem informasi dan teknologi informasi yang akan diterapkan pada SMK swasta dengan harapan nantinya mampu meningkatkan kualitas pelayanan serta integritas sekolah. Menggunakan metodologi Ward and Peppard dengan tools: PEST, Five Forces Competitive, Value Chain, SWOT, Critical Success Factors, McFarlan's Strategic Grid dan BCG. Dengan menghasilkan dokumen portofolio berupa aplikasi sistem informasi dan teknologi informasi dalam jangka waktu hingga tahun 2024 yang nantinya bisa dimanfaatkan sebagai landasan untuk mengembangkan layanan pendidikan melalui bantuan sumber daya teknologi (Widagdo, dkk, 2018).

Penelitian lainnya dengan judul Perencanaan Strategis Sistem Informasi SMP Plus Citra Madinatul Ilmi Banjarbaru membahas tentang meningkatkan mutu dan pelayanan terbaik kepada siswa dan orang tua siswa, dengan tiga sasaran utama yaitu: memperbaiki efisiensi kerja dengan melakukan otomatis berbagai proses yang mengelola informasi, meningkatkan keefektifan manajemen dengan memuaskan kebutuhan informasi, meningkatkan keunggulan kompetitif organisasi dengan merubah gaya dan cara berbisnis. Dengan menggunakan pendekatan analisis Value Chain untuk internal dan analisis PEST untuk eksternal dan pemetaannya menggunakan portofolio McFarlan. Hasil Penelitian yaitu sebuah kerangka kerja rencana strategis sistem informasi berupa blueprint pengembangan perencanaan strategis sistem informasi mendatang dengan menggunakan McFarlan Strategic Grid untuk pemetaan aplikasi sistem informasi dan urutan susunan prioritas pengembangan aplikasi sistem informasi (Khairullah, 2016).

Berdasarkan penelitian-penelitian sebelumnya sebagai acuan penulis dalam menyusun penelitian ini.
Harapannya hasil akhir penelitian ini dapat membantu SMP Negeri 4 Salatiga dalam mengoptimalkan sumber daya sistem informasi yang tersedia.

Metode Ward and Peppard digunakan untuk mengevaluasi seberapa baik pengimplementasian strategi sistem informasi pada SMP Negeri 4 Salatiga. Setelah mengetahui kondisi lingkungan bisnis internal maupun eksternal dan kondisi sistem informasi internal maupun eksternal saat ini, maka dapat diketahui keselarasan strategi bisnis dan strategi sistem informasi. Keluaran dari metodologi ini yaitu portofolio sistem informasi yang selaras dan bahan acuan implementasi yang akan datang untuk SMP Negeri 4 Salatiga dalam bentuk roadmap.

\section{RUANG LINGKUP}

Dalam penelitian ini permasalahan mencakup:

1. Cakupan permasalahan terletak pada penerapan sistem informasi yang belum terintegrasi menyebabkan terhambatnya proses bisnis.

2. Batasan-batasan penelitian hanya berfokus pada perencanaan sistem informasi di SMP Negeri 4 Salatiga.

3. Rencana hasil yang didapatkan yaitu usulan sistem informasi dan roadmap sebagai bahan acuan untuk diimplementasikan oleh SMP Negeri 4 Salatiga ke depannya.

\section{BAHAN DAN METODE}

Berikut paparan bahan kajian dan metode yang digunakan serta tahapan penelitian yang dilakukan.

\subsection{Sistem Informasi}

Sistem informasi merupakan perpaduan antara orang, perangkat keras, perangkat lunak, teknologi informasi dan data yang dikumpulkan, diolah dan disebarkan dalam sebuah organisasi (Anggraeni, 2017).

Sistem informasi merupakan perangkat dengan menggunakan teknologi untuk mengumpulkan, memproses, menyimpan, menyebarkan serta menyajikan informasi yang dibutuhkan organisasi (Yobel \& Sitokdana, 2020).

\subsection{Perencanaan Strategis Sistem Informasi}

Perencanaan strategis sistem informasi merupakan suatu proses penyusunan rencana jangka panjang terhadap sumber daya yang dikembangkan dan digunakan untuk mencapai tujuan bisnis organisasi dalam waktu tertentu (Yobel \& Sitokdana, 2020). Perencanaan strategis sistem informasi merupakan proses identifikasi portofolio aplikasi sistem informasi yang akan menunjang dalam pelaksanaan dan merealisasikan tujuan bisnis organisasi.

Perencanaan strategis sistem informasi mempelajari bagaimana pengaruh sistem informasi terhadap kinerja bisnis dan menjelaskan berbagai kebutuhan organisasi supaya strategi SI selaras dengan strategi bisnis organisasi (Karsana, dkk, 2019). 


\subsection{Metodologi Ward And Peppard}

Metodologi yang digunakan dalam penelitian ini yaitu metodologi Ward and Peppard. Metode ini dimulai dari analisis kondisi lingkungan bisnis internal dan eksternal kemudian analisis lingkungan sistem informasi dan teknologi informasi internal dan eksternal.

Analisis lingkungan bisnis internal dan eksternal adalah analisis kondisi bisnis utama maupun bisnis pendukung dan mengetahui kekuatan serta kelemahan untuk memaksimalkan peluang ancaman dari luar. Analisis lingkungan sistem informasi dan teknologi informasi internal eksternal adalah analisis software dan hardware yang sudah diterapkan dalam proses bisnis saat ini.

Dalam penelitian ini menggunakan alat bantu analisis Value Chain, SWOT dan Mc Farlan Strategic Grid dalam menyusun perencanaan strategis pada SMP Negeri 4 Salatiga. Berikut skema perencanaan strategis sistem informasi dan teknologi informasi Ward dan Peppard yang terdapat pada Gambar 1.

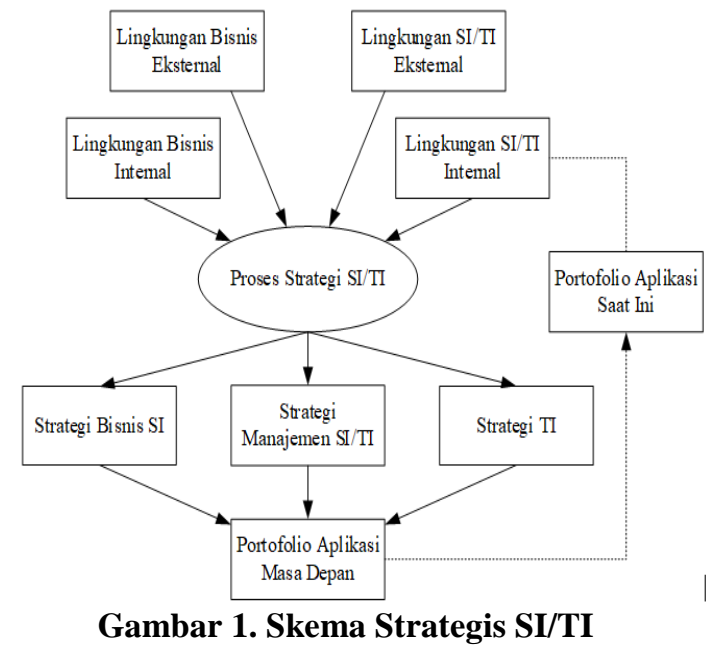

(Ward \& Peppard 2002)

Metodologi ini terdiri dari tahapan masukan (input) dan tahapan keluaran (output) (Ward \& Peppard, 2002). Tahapan masukan (input) terdiri dari:

1. Lingkungan Bisnis Internal, mencakup aspek strategi proses bisnis saat ini, sumber daya, tujuan serta nila nilai budaya bisnis organisasi.

2. Lingkungan Bisnis Eksternal, mencakup aspek keuangan, industri, kompetitor perusahaan.

3. Lingkungan SI/TI Internal, mencakup kondisi SI dan TI perusahaan dari sudut pandang bisnis saat ini, keterlibatan terhadap bisnis, prasarana teknologi, serta kondisi portofolio sistem informasi dan teknologi informasi yang sudah ada, serta kemampuan tenaga ahli untuk menangani sistem informasi dan teknologi informasi yang telah dijalankan.

4. Lingkungan SI/TI Eksternal, mencakup kondisi teknologi, kemungkinan penggunaannya, serta fungsi dan bentuk teknologi yang digunakan oleh pesaing, customer dan pemasok.

Tahapan keluaran (output) dilakukan untuk menghasilkan portofolio perencanaan strategis SI yang isinya terdiri dari:

1. Strategi Bisnis SI/TI, mencakup bagaimana cara unit bisnis dalam memanfaatkan sistem informasi yang berfungsi untuk mencapai sasaran bisnis.

2. Strategi TI, mencakup kebijakan dan strategi dalam mengelola teknologi informasi dan sumber daya manusia.

3. Strategi Manajemen SI/TI, mencakup elemen umum yang diterapkan di organisasi untuk memastikan konsistensi penerapan kebijakan SI.

4. Portofolio Aplikasi Saat Ini, mencakup rincian mengenai penggunaan aplikasi SI/TI perusahaan saat ini.

5. Portofolio Aplikasi Masa Depan, mencakup rincian usulan aplikasi yang digunakan di masa depan sesuai dengan analisis yang telah dilakukan.

\subsection{Tahapan Penelitian}

Metode yang digunakan dalam penelitian di SMP Negeri 4 Salatiga yaitu metode kualitatif, yang merupakan pengamatan, wawancara atau menelaah dokumen.

Pemilihan metode ini karena lebih mudah mengetahui apa saja yang dibutuhkan oleh organisasi perusahaan serta responden dapat menjelaskan kondisi yang sebenarnya kepada peneliti sehingga data yang didapatkan bersifat primer. Berikut tahapan penelitian yang dilakukan pada SMP Negeri 4 Salatiga seperti pada Gambar 2, dijabarkan berikut:

1. Identifikasi Masalah

Pada tahap awal penelitian yaitu peneliti mendapatkan gambaran mengenai masalah yang dihadapi oleh SMP Negeri 4 Salatiga dengan proses observasi.

2. Studi Literatur

Tahap ini peneliti melakukan tinjauan terhadap berbagai penelitian terdahulu yang topiknya berkaitan dengan penelitian sekarang sebagai referensi dalam penulisan rencana strategis sehingga dapat memperkaya topik yang akan dibahas.

3. Pengumpulan Data

Tahap ini peneliti melakukan observasi dan wawancara dengan wakil kepala sekolah, beberapa guru dan beberapa staf SMP Negeri 4 Salatiga.

4. Analisis Data

Tahap ini peneliti menganalisis data yang telah di kumpulkan melalui proses sebelumnya sehingga dapat dijadikan bahan untuk penyusunan rencana strategis.

5. Penulisan

Pada tahap ini, pembuatan rencana strategis dengan menggunakan data - data yang sudah dikumpulkan sehingga dapat memberikan usulan sistem informasi ke depannya. 


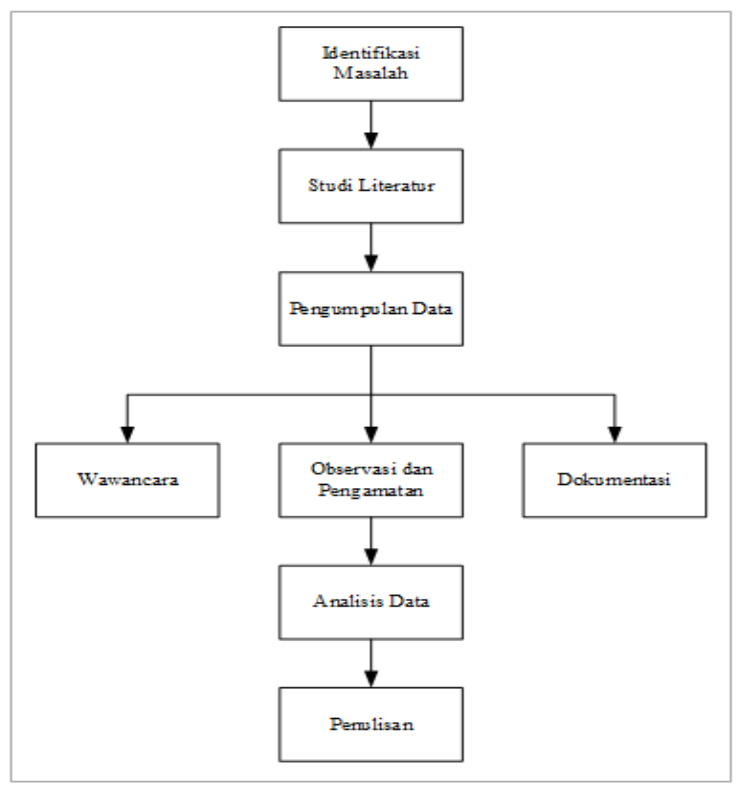

Gambar 2. Tahapan Penelitian

\section{PEMBAHASAN}

Tahap awal sebelum menganalisis lingkungan bisnis internal eksternal, perlunya mengidentifikasi visi misi dan tujuan dari organisasi terlebih dahulu agar dapat mengetahui gambaran keadaan organisasi tersebut dan membuat perencanaan strategis. Berikut identifikasi visi misi dan tujuan SMP Negeri 4 Salatiga.

\subsection{Identifikasi Visi Misi dan Tujuan}

Berikut visi dan misi serta tujuan SMP Negeri 4 Salatiga.

1. Visi

Terwujudnya sekolah yang unggul prestasi, santun berbudi, tangguh berkompetisi, sadar bertakwa dan ramah lingkungan.

2. Misi

1) Menerapkan model pembelajaran intensif meliputi pembelajaran interaktif, aplikasi dan akselerasi.

2) Meningkatkan disiplin belajar dan etos kerja.

3) Melaksanakan program simpati, kepedulian dan pengembangan diri.

4) Membudayakan santun dalam berbicara, cipta, rasa dan karsa.

5) Membiasakan sikap sportif dalam berkompetisi meraih prestasi.

6) Melaksanakan program latihan keorganisasian dan kepemimpinan.

7) Mengaktualisasikan semangat belajar mengajar dengan cara berfikir tingkat tinggi.

8) Mempraktikkan iman dan takwa dalam kehidupan sehari-hari.

9) Menciptakan lingkungan sehat, bersih, indah, nyaman dan aman.
3. Tujuan

SMP Negeri 4 Salatiga bertujuan untuk menghasilkan siswa siswi yang aktif dan berprestasi dalam bidang akademik maupun nonakademik dan mempunyai sikap yang sopan santun, bertakwa dan ramah lingkungan. Mengamalkan dan menerapkan nilai-nilai pancasila dalam kehidupan sehari-hari pada peserta didik.

\subsection{Analisis Lingkungan Bisnis Internal dan Eksternal}

Berikut analisis lingkungan internal dan eksternal dengan alat bantu analisis value chain dan SWOT, seperti:

\subsubsection{Analisis Value Chain}

Analisis Value Chain, merupakan analisis bisnis internal untuk memetakan seluruh aktivitas yang ada di suatu organisasi. Proses analisis value chain ini digunakan untuk menggambarkan dan mengelompokkan aktivitas proses bisnis, yaitu aktivitas utama dan aktivitas pendukung (Wibowo, Utami \& Nasiri, 2018). Pemetaan aktivitas utama dan aktivitas pendukung pada SMP Negeri 4 Salatiga seperti pada Gambar 3.

\begin{tabular}{|c|c|c|c|c|c|}
\hline 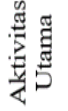 & $\begin{array}{l}\text { Penerimaan } \\
\text { Siswa Baru }\end{array}$ & $\begin{array}{l}\text { Proses } \\
\text { Belajar } \\
\text { Mengajar }\end{array}$ & $\begin{array}{l}\text { Evaluasi } \\
\text { Belajar }\end{array}$ & $\begin{array}{l}\text { Kelulusan } \\
\text { Siswa }\end{array}$ & $\begin{array}{l}\text { Layanan } \\
\text { Informasi } \\
\text { Sekolah }\end{array}$ \\
\hline \multirow{4}{*}{ 总总 } & \multicolumn{5}{|c|}{$\begin{array}{l}\text { Infrastruktur Administrasi: Manajemen Administrasi, } \\
\text { Manajemen Keuangan, Manajemen Akademik }\end{array}$} \\
\hline & \multicolumn{5}{|c|}{ Sumber Daya Manusia: Manajemen Sumber Daya Manusia } \\
\hline & \multicolumn{5}{|c|}{ Teknologi: Pengembangan ICT } \\
\hline & \multicolumn{5}{|c|}{$\begin{array}{l}\text { Pengadaan: Manajemen Sarana Prasarana, Manajemen } \\
\text { Perpustakaan }\end{array}$} \\
\hline
\end{tabular}

\section{Gambar 3. Value Chain Analysis SMP Negeri 4 Salatiga.}

Berdasarkan analisis value chain pada gambar 3 diatas maka dapat diidentifikasi sebagai berikut:

1. Aktivitas Utama

Aktivitas utama pada SMP Negeri 4 Salatiga terdiri dari:

1) Penerimaan Siswa Baru, merupakan aktivitas pokok yang dilakukan oleh SMP Negeri 4 Salatiga setiap tahunnya.

2) Proses Belajar Mengajar, dimana guru dan peserta didik saling berinteraksi. Guru memberikan dan menyampaikan materi pembelajaran kepada peserta didik kemudian peserta didik menerima materi tersebut.

3) Evaluasi Belajar, merupakan pengukuran dan penilaian yang dilakukan dua kali setahun yaitu setiap akhir semester ganjil dan semester genap. Evaluasi pembelajaran untuk mengukur perkembangan, tingkat kemajuan dan 
pencapaian peserta didik beserta keefektifan guru dalam mengajar.

4) Kelulusan Siswa, peserta didik dinyatakan lulus jika sudah memenuhi ketentuan dan menyelesaikan program pembelajaran dengan hasil evaluasi setiap semester.

5) Layanan Informasi Sekolah, untuk menyampaikan informasi internal maupun eksternal sekolah kepada peserta didik.

2. Aktivitas Pendukung

Aktivitas pendukung pada SMP Negeri 4 Salatiga terdiri dari:

1) Infrastruktur Administrasi: Manajemen administrasi, manajemen keuangan dan manajemen akademik. Mengelola administrasi sekolah secara keseluruhan untuk meningkatkan mutu sekolah, mengelola anggaran dan laporan keuangan, merencanakan kurikulum pendidikan.

2) Sumber Daya Manusia: Manajemen sumber daya manusia. Mengelola perekrutan, administrasi, laporan kinerja, pelatihan internal dan rapat kerja guru dan karyawan.

3) Teknologi: Pengembangan ICT. Mengelola sistem informasi yang tersedia seperti sistem informasi akademik dan website sekolah.

4) Pengadaan: Manajemen sarana prasarana dan manajemen perpustakaan. Mengelola rencana kebutuhan sarana dan prasarana, mengelola perpustakaan sebagai wadah bagi peserta didik menambah ilmu dan wawasan (Hanafiah \& Junaedi, 2020).

\subsubsection{Analisis SWOT}

Analisis SWOT digunakan untuk mengevaluasi kekuatan dan kelemahan sumber daya yang dimiliki oleh suatu organisasi. Mengetahui peluang dan menggunakan kelemahan untuk menghadapi ancaman dari luar (Mukti, 2017). Analisis kekuatan (strengths), kelemahan (weakness), Peluang (Opportunities) dan Ancaman (Threat) yang terdapat pada SMP Negeri 4 Salatiga dapat di identifikasi sebagai berikut.

1. Kekuatan (Strength): Semua guru berpendidikan S1, 97\% guru sudah berstatus PNS, kemampuan dasar siswa siswi baik, memiliki program unggul yaitu Nepatsa Hebat 19-21 dan Batinku Padang, memiliki berbagai ekstrakurikuler, memiliki sarana prasarana yang memadai untuk mendukung proses belajar mengajar, dana untuk biaya operasional mencukupi dan letak sekolah yang strategis berada di tengah kota.

2. Kelemahan (Weakness): Masih adanya beberapa guru yang berstatus guru honorer.

3. Peluang (Opportunities): Menghasilkan lulusan berprestasi yang siap melanjutkan pendidikan menengah atas (SMA), menambahkan kepercayaan orang tua peserta didik, meningkatkan hubungan baik dengan dinas pendidikan kota Salatiga.
4. Ancaman (Threat): Kebijakan dinas pendidikan yang berubah, sekolah kompetitor sejenis dalam setiap perlombaan akademis dan non-akademis antar sekolah.

5. Strategi S-O (Strenghts-Opportunities): Meningkatkan mutu sekolah, mengembangkan lingkungan sekolah yang HEBAT (Harmoni, Etika, Bestari, Aktif, Taqwa), mempertahankan dan meningkatkan potensi peserta didik dalam bidang akademis maupun non-akademis, meningkatkan kinerja tenaga pendidik melalui pelatihan pelatihan intensif.

6. Strategi W-O (Weaknesses-Opportunities): Mengoptimalkan pengembangan profesi guru secara internal maupun eksternal dengan mengutamakan kualitas, mengembangkan pembelajaran yang efektif, aktif, kreatif dan inovatif, mengoptimalkan kegiatan ekstrakurikuler dan program Hebat 19-21 dan Batinku Padang.

7. Strategi S-T (Strenghts-Threats): Meningkatkan kemampuan dan keterampilan peserta didik, menyediakan media berbasis ICT dan memanfaatkan sarana prasarana yang ada dengan maksimal dalam proses pembelajaran peserta didik, meningkatkan prestasi akademis dan non-akademis dengan maksimal (Setyawati, 2017).

8. Strategi W-T (Weaknesses-Threats): Mengikuti pelatihan pengembangan profesi yang diadakan oleh dinas pendidikan untuk meningkatkan kualitas kinerja para guru, monitoring yang efektif dan efisien dari kepala sekolah, membentuk tim evaluasi khusus untuk memantau perkembangan kualitas profesi guru (Fahana, 2018).

\subsection{Analisis Lingkungan SI Internal dan Eksternal}

Dalam mengidentifikasi sistem informasi di SMP Negeri 4 Salatiga, maka perlunya analisis lingkungan internal SI yang digunakan pada saat ini untuk mengetahui sumber daya sistem informasi yang tersedia, dan sumber daya manusia dalam menggunakan sistem informasi tersebut.

Berikut daftar sistem informasi yang digunakan oleh SMP Negeri 4 Salatiga saat ini seperti pada tabel 1. 
Tabel 1. Daftar Sistem Informasi pada SMP Negeri 4 Salatiga

\begin{tabular}{|c|l|l|l|}
\hline Nama SI & Pengguna & Status & $\begin{array}{l}\text { Jenis } \\
\text { Aplikasi }\end{array}$ \\
\hline 1. Dapodik & $\begin{array}{l}\text { Kepala } \\
\text { Sekolah dan } \\
\text { Tata Usaha }\end{array}$ & Terintegrasi & Website \\
\hline 2. PPDB & $\begin{array}{l}\text { Guru, Calon } \\
\text { Siswa, Wali } \\
\text { Murid, } \\
\text { Masyarakat } \\
\text { Umum }\end{array}$ & Terintegrasi & Website \\
\hline $\begin{array}{l}\text { 3. Slim } \\
\text { Siswa, Kepala } \\
\text { Perpustakaan, } \\
\text { Guru dan Staf }\end{array}$ & Terintegrasi & $\begin{array}{l}\text { Website, } \\
\text { Desktop }\end{array}$ \\
\hline 4. E-Raport & $\begin{array}{l}\text { Siswa dan } \\
\text { Guru }\end{array}$ & Terintegrasi & $\begin{array}{l}\text { Website, } \\
\text { Mobile }\end{array}$ \\
\hline $\begin{array}{l}\text { 5. Absensi } \\
\text { (Fingerpri } \\
\text { nt })\end{array}$ & $\begin{array}{l}\text { Kepala } \\
\text { Sekolah, Guru } \\
\text { dan Staf }\end{array}$ & Terintegrasi & Desktop \\
\hline $\begin{array}{l}\text { 6. Company } \\
\text { Profile } \\
\text { Sekolah }\end{array}$ & $\begin{array}{l}\text { Guru, Siswa, } \\
\text { Wali Murid } \\
\text { dan } \\
\text { Masyarakat } \\
\text { Umum }\end{array}$ & Belum & Terintegrasi \\
\hline
\end{tabular}

\subsection{Strategi Bisnis Sistem Informasi}

Berdasarkan daftar sistem informasi pada tabel 1 diatas maka SMP Negeri 4 Salatiga perlunya memperbarui sistem informasi yang ada untuk menunjang proses bisnis berjalan dengan lancar. Memperbarui Dapodik dan PPDB sesuai dengan jadwal yang ditentukan oleh pemerintah. memperbarui Slim, E-Raport, Absensi (Fingerprint) dan memperbarui tampilan Company Profile sekolah dengan tampilan terbaru agar lebih user friendly.

\subsection{Strategi Manajemen Sistem Informasi}

Berdasarkan hasil wawancara, teknisi khusus yang menangani serta mengontrol hardware dan software pada SMP Negeri 4 Salatiga yaitu guru TIK (Agnes \& Wijaya, 2020).

\subsection{Usulan Aplikasi}

Berdasarkan hasil analisis lingkungan internal maupun eksternal sistem informasi pada SMP Negeri 4 Salatiga, maka terdapat beberapa usulan pengembangan sistem informasi, yaitu:

1. Sipras, adalah sistem untuk mengelola sarana dan prasarana.

2. Sikewa, adalah sistem untuk mengelola kegiatan kesiswaan atau siswa.

3. Sikelulusan, adalah sistem untuk mengelola kelulusan siswa.

4. Sialumni, adalah sistem untuk mengelola alumni.

5. E-Learning, adalah sistem untuk media pembelajaran interaktif.

Berikut sistem informasi yang penulis usulkan untuk SMP Negeri 4 Salatiga yang terdapat pada tabel 2.
Tabel 2. Daftar Usulan Sistem Informasi pada SMP Negeri 4 Salatiga

\begin{tabular}{|c|c|c|c|}
\hline Nama SI & Pengguna & Status & $\begin{array}{l}\text { Jenis } \\
\text { Aplikasi }\end{array}$ \\
\hline 1. Sipras & $\begin{array}{l}\text { Bagian } \\
\text { Sarana dan } \\
\text { Prasarana }\end{array}$ & $\begin{array}{l}\text { Baru dan } \\
\text { Belum } \\
\text { diimplement } \\
\text { asikan }\end{array}$ & Website \\
\hline 2. Sikewa & $\begin{array}{l}\text { Kepala } \\
\text { sekolah, } \\
\text { Bagian } \\
\text { Kesiswaan, } \\
\text { Siswa }\end{array}$ & $\begin{array}{l}\text { Baru dan } \\
\text { Belum } \\
\text { diimplement } \\
\text { asikan }\end{array}$ & $\begin{array}{l}\text { Website, } \\
\text { Mobile }\end{array}$ \\
\hline 3. Sikelulusan & $\begin{array}{l}\text { Kepala } \\
\text { Sekolah, } \\
\text { Guru, Siswa }\end{array}$ & $\begin{array}{l}\text { Baru dan } \\
\text { Belum } \\
\text { diimplement } \\
\text { asikan }\end{array}$ & $\begin{array}{l}\text { Website, } \\
\text { Mobile }\end{array}$ \\
\hline 4. Sialumni & Staf, Alumni & $\begin{array}{l}\text { Baru dan } \\
\text { Belum } \\
\text { diimplement } \\
\text { asikan }\end{array}$ & $\begin{array}{l}\text { Website, } \\
\text { Mobile }\end{array}$ \\
\hline 5. E-Learning & Guru, Siswa & $\begin{array}{l}\text { Baru dan } \\
\text { Belum } \\
\text { diimplement } \\
\text { asikan }\end{array}$ & Website \\
\hline
\end{tabular}

Berdasarkan usulan sistem informasi pada tabel 2 diatas akan dipetakan sesuai fungsinya masing-masing ke dalam matriks Portofolio McFarlan Strategic Grid untuk menganalisis suatu sistem informasi atau aplikasi di SMP Negeri 4 Salatiga berdasarkan kondisi saat ini maupun kondisi yang direncanakan di masa mendatang (Fahana, dkk, 2016). Adapun matriks McFarlan Strategic Grid yang digunakan untuk pemetaan aplikasi mendatang di SMP Negeri 4 Salatiga dapat dilihat pada Tabel 3.

Tabel 3. Pemetaan Sistem Informasi SMP Negeri 4 Salatiga

\begin{tabular}{|l|l|}
\hline Strategic & High potential \\
\hline Sikewa (Baru) & $\begin{array}{l}\text { 1. Sipras (Baru) } \\
\text { 2. Sialumni(Baru) }\end{array}$ \\
\hline E-Learning (Baru) & Sikelulusan (Baru) \\
\hline Key operational & Support \\
\hline
\end{tabular}

\subsection{Pemetaan Implementasi Aplikasi}

Rencana implementasi usulan strategis sistem informasi dalam jangka waktu 5 tahun yang akan datang (2021-2025) disusun dalam bentuk roadmap (Harir, Soedijono \& Soyan, 2020) seperti pada tabel 4.

Tabel 4. Pemetaan Implementasi usulan SI SMP Negeri 4 Salatiga

\begin{tabular}{|l|l|l|l|l|l|}
\hline Nama SI & 2021 & 2022 & 2023 & 2024 & 2025 \\
\hline E-Learning & \multicolumn{2}{|l|}{ Key Operational } & & & \\
\hline Sikewa & & Strategic & & & \\
\hline Sipras & & & \multirow{2}{*}{ High Potential } & \\
\cline { 1 - 3 } Sialumni & & & & & \\
\cline { 1 - 3 } Sikelulusan & & & & & Support \\
\hline
\end{tabular}


Keterangan tabel 4:

1. Key Operational: E-Learning merupakan sistem yang harus di kembangkan pada tahap pertama karena memberikan kemudahan kepada SMP Negeri 4 Salatiga dalam proses bisnisnya terutama dalam proses pembelajaran interaktif.

2. Strategic: Sikewa merupakan sistem yang kembangkan tahap kedua karena sistem ini sangat penting dalam proses bisnis, dimana sistem ini yang mengelola kegiatan kesiswaan atau siswa. Untuk mempertahankan bisnisnya, SMP Negeri 4 Salatiga sangat perlu mengorganisir kegiatan siswa siswinya, baik kegiatan internal maupun kegiatan eksternal sekolah.

3. High Potential: Sipras dan Sialumni merupakan sistem yang dikembangkan pada tahap ketiga karena sistem ini akan berpengaruh dalam mendukung proses bisnis ke depannya. Sipras akan sangat membantu dalam memanajemen sarana prasarana di SMP Negeri 4 Salatiga, serta Sialumni merupakan sistem yang mengelola para alumni SMP Negeri 4 Salatiga agar komunikasi alumni dengan sekolah tetap terjaga.

4. Support: Si kelulusan merupakan sistem yang dikembangkan pada tahap keempat karena sistem ini mengelola informasi mengenai proses kelulusan. Sistem ini mempermudah siswa dan orang tua dalam melihat informasi tentang kelulusan siswa SMP Negeri 4 Salatiga.

\section{KESIMPULAN}

Berdasarkan hasil analisis dalam penelitian ini, menunjukkan bahwa SMP Negeri 4 Salatiga telah menerapkan sistem informasi namun belum terintegrasi dan belum dimanfaatkan secara maksimal sehingga proses bisnis tidak efisien dan terhambat. Penyusunan rencana strategis sistem informasi menggunakan metode Ward and Peppard dengan alat bantu analisis value chain, SWOT, McFarlan Strategic Grid yang menghasilkan portofolio aplikasi. Maka dari itu, terdapat rekomendasi pengembangan sistem informasi seperti: Sipras, Sikewa, Si kelulusan, Sialumni dan E-Learning yang dipetakan kedalam Portofolio McFarlan Strategic Grid yang dapat diimplementasikan oleh SMP Negeri 4 Salatiga dalam kurun waktu 5 tahun ke depan. Diharapkan dapat memberi manfaat bagi proses bisnis sehingga dapat meningkatkan kualitas layanan dan integritas sekolah serta SMP Negeri 4 Salatiga dapat berkembang.

\section{SARAN}

Penelitian ini hanya melakukan perencanaan strategis sistem informasi yang menghasilkan sebuah rekomendasi aplikasi, mungkin penelitian selanjutnya dapat melanjutkan hingga ke tahap implementasi sistem informasi baik menggunakan pemrograman web maupun desktop yang sudah direncanakan.

\section{DAFTAR PUSTAKA}

Agnes, A., Wijaya, A. F. 2020. Perencanaan Strategis Sistem Informasi menggunakan Metodologi Ward dan Peppard (Studi Kasus: Nusatovel Salatiga). Journal of Information Systems and Informatics Vol. 2, No. 2, September 2020 e-ISSN: 26564882 p-ISSN: 2656-5935

Anggraeni, E. Y. 2017. Pengantar Sistem Informasi. Penerbit Andi.

Fahana, J. 2018. Perencanaan Strategis Sistem Informasi untuk Pengelolaan Guru Sekolah Muhammadiyah. Jurnal Ilmu Teknik Elektro Komputer dan Informatika (JITEKI) Vol. 4, No. 1.

Fahana, J., Utami, E., Amborowati, A. 2016. Perencanaan Strategis Sistem Informasi Untuk Pengelolaan Kepemimpinan Di Sekolah Muhammadiah Kota Yogyakarta. Jurnal Ilmiah DASI Vol. 17 No. 2 Juni 2016 ISSN: 1411-3201

Hanafiah, H., Junaedi, E. 2020. Perencanaan Strategis Sistem Informasi Dan Teknologi Informasi (SI/TI) Perpustakaan Di SMA Negeri 1 Baleendah. Jurnal Sistem Informasi - J-SIKA Volume 02 Nomor 01, Juni 2020: 34-41 ISSN: 2716 - 4195

Handayani, F. S. 2018. Perencanaan Strategi Sistem Informasi Dalam Kegiatan Penelusuran Minat Siswa Sekolah Menengah Pertama. Jurnal Mikrotik Vol. 8/No. 1.

Harir, A. R., Soedijono, B., Soyan, A. F. 2020. Analisis Perencanaan Strategis Sistem Informasi Pada Madrasah Tsanawiyah Negeri. JURNAL SISTEM INFORMASI DAN TEKNOLOGI INFORMASI Vol. 9, No. 2, Oktober 2020

Johannis, M. F., Tanaamah, A. R., Chernovita, H. P. 2019. Perencanaan Strategis Sistem Informasi Menggunakan Metode Ward and Peppard (Studi Kasus : CV. Grafika Prima Mitra Ambon). SEBATIK 1410-3737

Karsana, I. W. W., Candiasa, I. M., Dantes, G. R. 2019. Perencanaan Strategis Sistem Informasi dan Teknologi Informasi Menggunakan Framework Ward \& Peppard Pada Sekolah Bali Kiddy. Jurnal Ilmu Komputer Indonesia (JIKI) Vol: 4, No. 1.

Khairullah. 2016. Perencanaan Strategis Sistem Informasi SMP Plus Citra Madinatul Ilmi Banjarbaru. Journal Speed - Sentra Penelitian Engineering dan Edukasi - Volume 8 No 2

Manoppo, F. 2017. Perencanaan Strategis Sistem Informasi Menggunakan Metode Ward and Peppard (Studi Kasus: Pada STMIK Parna Raya Manado). 2 nd Seminar Nasional IPTEK Terapan (SENIT) ISSN: 2579-9045 Tegal - Indonesia, 15-17 Mei 2017 ISBN: 978-602-74355-1-3

Mukti, Y. I. 2017. Perencanaan Strategis Sistem Informasi Dan Teknologi Informasi Pada Sekolah 
Menengah Kejuruan Negeri 2 Pagar Alam. Jurnal Ilmiah Betrik, Vol. 08, No.02, Agustus 2017

Setiyanti, A. A., Palekahelu, D. T., Sediyono, E. 2016. Perencanaan Pengembangan Sumber Daya Teknologi Informasi dan Komunikasi dalam Mendukung Rencana Strategis di Sekolah Menengah. Jurnal Buana Informatika, Volume 7, Nomor 2, April 2016:95-104

Setyawati, S. 2017. Pelaksanaan Administrasi Sekolah Unggul di SMP Negeri 7 Kuantan Tengah Kabupaten Kuantan Singingi. Jurnal Ilmu Pendidikan Sosial, sains, dan Humaniora Vol. 3 No. 3.

Sujoko, E. 2017. Strategi Peningkatan Mutu Sekolah Berdasarkan Analisis SWOT di Sekolah Menengah Pertama. Jurnal Kelola, Vol. 4, No. 1.

Wibowo, D. F. K. S., Utami. E., Nasiri. A. 2018. Perencanaan Strategis Sistem Informasi Untuk Meningkatkan Keunggulan Bersaing Sekolah Swasta Inklusi. Jurnal IT CIDA Vol. 4 No. 1 Juni 2018 ISSN: 2477-8133 e-ISSN: 2477-8125

Widagdo, S. V., Prastiwi, Alamsah, Kamisutara, M. 2018. Perencanaan Strategis Sistem Informasi Untuk Meningkatkan Layanan Pendidikan Menggunakan Metode Ward and Peppard. Seminar Nasional Aplikasi Teknologi Informasi (SNATi) 2018 ISSN: 1907 - 5022 Yogyakarta.

Yobel, E. C. C., Sitokdana, M. N. N. 2020. Perencanaan Strategis Sistem Informasi Menggunakan Metode Ward and Peppard di Perusahaan PT Pura Barutama (Unit PM1O). SEBATIK 1410-3737 